\title{
A GEOGRAFIA DO PRODUTO INTERNO BRUTO BRASILEIRO E AS TENDÊNCIASDE CRESCIMENTO POPULACIONAL NA REDE DE LOCALIDADES CENTRAIS
}

\author{
RalfoMatos* \\ Ricardo Alexandrino Garcia
}

\section{Resumo}

As tentativas de se estabelecer vínculos de determinação entre os processos econômicos e osdemográficos remontam aos pensadores dos séculos XVIII e XIX e ainda persistem até hoje como um desafio à teoria em diversos campos do conhecimento. $\mathrm{O}$ incremento das taxas do produto nacional abre oportunidades difusas para pessoas e atividade e gera efeitos multiplicadores de toda a sorte sobre o restante da economia. Mas a expansão do PIB, por força dos processos de reestruturação e inovação tecnológica, pode também significar redução de postos de trabalho, eliminação/substituição de atividades e profissões, frustração nos trabalhadores, enfim marginalização de áreas e cidades distantes dos núcleos dinâmicos da economia. Nesse trabalho far-se-á uso da representação espacial dos fenômenos estudados, a fim de usufruir-se do grande poder de síntese que os mapas possuem, mas também de evidenciar que os processos de distribuição e redistribuição de pessoas e atividades só podem ser amplamente reconhecidos se as territorialidades que lhes são subjacentes forem explicitadas, de preferência com todas as suas dimensões intrínsecas como posição, localização relativa e tamanho. Para tanto, utilizar-se-á uma representação cartográfica do território brasileiro baseada na premissa da hierarquia urbana e do sistema de localidades centrais, a partir da qual pontos, redes e superfícies se conjugam e auxiliam a visualização mais simplificada e completa dos fenômenos estudados em todo o país. Trata-se de proposta já apresentada em vários trabalhos (Matos, 2002; Matos e Braga, 2002; Matos e Ferreira, 2005) aqui denominada de Rede de Localidades Centrais (RLC).

Palavras chave:PIB; crescimento populacional; migração, rede de localidades; geografia econômica brasileira.

\footnotetext{
'Prof. Adjunto do Departamento de Geografia do ICG/UFMG, Doutor emDemografia.

^Prof. Adjunto do Departamento de Geografia do ICG/UFMG, Doutor emDemografia.

Cadernos do Leste 


\section{1 - INTRODUÇÃO}

As tentativas de se estabelecer vínculos de determinação entre os processos econômicos e os demográficos remontam aos pensadores dos séculos XVIII e XIX e ainda persistem até hoje como um desafio à teoria em diversos campos do conhecimento. Apesar de todos os esforços de teorização feitos sobre tais processos, não é incomum constatar que as exceções frequentemente prevalecem diante das regras. Não há, de fato, um enunciado geral, passível de repetidas comprovações empíricas, que assegure, por exemplo, que a dinâmica demográfica seja uma mera consequência da dinâmica econômica, embora essa assertiva ainda nos prenda a atenção na atualidade.

Mas também não há como discordar do fato de que a análise econômica só ganha mais consistência e profundidade se for acoplada à análise das taxas de crescimento da população, notadamente da população em idade ativa. Isto porque o monitoramento das taxas de desemprego tem de ser cotejado com o crescimento demográfico da população jovem, geralmente ávida por emprego em um mundo onde a eliminação de postos de trabalho já se tornou uma espécie de desígnio da modernidade ou contingência da era do conformismo.

De toda forma, tais medições envolvem questões de grande importância para vários países (como a França de 2005 e 2006), os quais só aparentemente teriam conquistado a estabilidade demográfica e econômica, após conviverem com variados tipos de dificuldades derivadas de desequilíbrios associados a guerras, crescimento econômico, aumento da produtividade, expansão do desemprego e subemprego, transição demográfica, envelhecimento rápido da população, aumento dos gastos sociais e até mesmo incremento da imigração.

Entretanto, não há como negar que o pior dos mundos é o da estagnação ou baixo crescimento econômico combinado com forte crescimento demográfico. $O$ incremento das taxas do produto nacional abre oportunidades difusas para pessoas e atividade e gera efeitos multiplicadores de toda a sorte sobre o restante da economia. Mas a expansão do PIB, por força dos processos de reestruturação e inovação tecnológica, pode também significar redução de postos de trabalho, eliminação/substituição de atividades e profissões, frustração nos trabalhadores excluídos do mercado de trabalho, desesperança entre os adultos não qualificados que se tornaram redundantes, violência urbana, enfim marginalização de áreas e cidades distantes dos núcleos dinâmicos da economia. O balanço entre o número de novos empregos criados, geralmente com requisitos mais elevados de escolarização e experiência, e os empregos eliminados pela reestruturação ainda é uma conta difícil de fechar, quase sempre resultando em ganhos a favor da economia e perdas para a população.

Tais questões continuam importantes na agenda dos debates contemporâneos, mas acrescidas de outros parâmetros que, de todo modo, introduzem muito mais complexidade às análises. Assim, 
tanto é mister investigar as associações entre a atividade econômica e a dinâmica demográfica, quanto fazer a mediação entre elas e outras questões que compõem a realidade social, especialmente aquelas que possuem forte inserção geográfica. Por exemplo: níveis de desigualdade, exclusão, pobreza e conflitos sociais em regiões e cidades; dotação de recursos naturais, formas de exploração e distribuição; níveis de comprometimento do meio ambiente, desperdício e matriz energética; características culturais e vocações regionais; entre outros.

Nesse trabalho far-se-á uso da representação espacial dos fenômenos estudados, a fim de usufruir-se do grande poder de síntese que os mapas possuem, mas também de evidenciar que os processos de distribuição e redistribuição de pessoas e atividades só podem ser amplamente reconhecidos se as territorialidades que lhes são subjacentes forem explicitadas, de preferência com todas as suas dimensões intrínsecas como posição, localização relativa e tamanho.

Para tanto utilizar-se-á uma representação cartográfica do território brasileiro baseada na premissa da hierarquia urbana e do sistema de localidades centrais, a partir da qual pontos, redes e superfícies se conjugam e auxiliam a visualização mais simplificada e completa dos fenômenos estudados em todo o país. Trata-se de proposta já apresentada em vários trabalhos (Matos, 2002; Matos e Braga, 2002; Matos e Ferreira, 2005) aqui denominada de Rede de Localidades Centrais (RLC) ${ }^{1}$, em clara alusão trabalho clássico de Walter Christaller, o alemão que formulou nos anos de 1930 a conhecida teoria do lugar central.

Inicialmente é feita uma análise do crescimento do PIB brasileiro considerando esse recorte espacial e suas três grandes porções regionais (frações), posteriormente, mantendo a mesma base espacial, são introduzidas várias estimativas demográficas focalizando o crescimento vegetativo, as taxas líquidas de migração, ao lado de um esforço de projetar essa população até o ano 2025, para finalmente concluímos com algumas considerações sobre as tendências de crescimento da produção de riqueza e o crescimento e distribuição da população no espaço.

\footnotetext{
${ }^{1} \mathrm{~A}$ rede urbana aqui adotada baseia-se no princípio teórico de fazer aflorar tanto os muitos municípiospopulosos, de grande e médio portes, comuns no Sudeste e Sul, quanto os municípios 'relativamente' pouco populosos, mas de importância estratégica em seus contextos regionais (como nos diversos casos envolvendo as regiões Norte e Centro-Oeste). Os critérios que orientam a seleção dos pontos (nódulos) da rede de cidades baseiam-se no peso populacional das localidades urbanas em seus estados e na existência de articulações viárias permanentes entre tais pontos, segundo o recorte físico-territorial de 1991. A RLC internalizava 184 pontos no ano 2000, apresentando uma hierarquização simplificada em dois níveis: o que aglutina as nove regiões metropolitanas originais, além de Brasília e Manaus, os denominados Centros Principais, e o que se refere aos 175 municípios restantes, aqui nomeados de Centros Intermediários. Os 5.069 municípios não pertencentes à rede são denominados de Demais Localidades. A RLC também divide-se em três frações - Norte, Nordeste e Centro Sul - o que permite análise fundada em grandes blocos regionais, vis-à-vis a hierarquização.A definição cartográfica privilegiou a produção de mapas com os pontos referentes às sedes dos municípios; alguns representam as regiões metropolitanas, outros referem-se ao conjunto restante dos principais municípios brasileiros.
}

Cadernos do Leste 


\section{2 - CRESCIMENTO DO PRODUTO INTERNO BRUTO NOS MUNICÍPIOS DAS FRAÇÕES DA REDE DELOCALIDADES CENTRAIS ENTRE 1999 E 2003}

O Produto Interno Bruto (PIB) a preços de mercado mede o total dos bens e serviçosproduzidos pelas unidades produtoras estabelecidas em uma determinada localidade num dado período. Corresponde, assim, a soma dos valores adicionados pelos diversos setores econômicos acrescidos dos impostos sobre produtos não incluídos na valoração da produção, menos subsídios. $\mathrm{O}$ PIB é, portanto, igual à soma do consumo final de bens e serviços valorados a preço de mercado sendo, também, equivalente à soma das rendas primárias. O cálculo do PIB dos municípios brasileiros baseiase na distribuição do valor adicionado das atividades econômicas das Contas Regionais do Brasil segundo essas localidades. Essa metodologia toma como base informações provenientes de órgãos estaduais de estatística, de secretarias estaduais de governo e de outras agências, sob a orientação da Coordenação de

Contas Nacionais do IBGE (IBGE, 2004).

O PIB brasileiro, segundo o IBGE, saltou de R\$ 973 milhões para 1,5 trilhões, entre 1999 e 2003 (Tabela 1). Isso não quer dizer que o aumento real foi de $60 \%$, pois, nesse caso, seria necessário considerar os efeitos da inflação do período. Tal qual à distribuição espacial da população, contudo, a produção de bens e serviços apresentou grande heterogeneidade entre as frações da RLC. A fração Centro-Sul concentrou, aproximadamente, 80\% do PIB brasileiro entre os anos de 1999 e 2003; a fração Nordeste apresentou um percentual bem mais modesto, algo por volta de $13 \%$, durante o mesmo período; e a fração Norte, embora internalize um ligeiro aumento de sua participação ao longo do período, seu percentual gravitou ao redor de $5 \%$.

Quando se analisa a participação dos centros urbanos no PIB, entre 1999 e 2003, verifica-se que os Centros Principais vêm, paulatinamente, cedendo espaço para os Centros Intermediários e Demais Localidades, dado que houve queda do peso do PIB dessas localidades em relação ao PIB total. A participação relativa dos grandes centros no PIB do país caiu de $44,8 \%$ para $40,8 \%$, ao passo que as participações dos Centros Intermediários e Demais Localidades subiram de 24,1\% para 25,3\% e de $31,0 \%$ para $33,8 \%$, respectivamente, durante esse período.

Mesmo que haja evidências de variação negativa do percentual de participação do PIB dos grandes centros, essas localidades ainda contribuem com mais de $40 \%$ do produto nacional. No entanto, interessantes diferenças foram encontradas na distribuição percentual do PIB pelos centros urbanos no interior das frações da RLC ao longo dos quatro anos considerados. Grosso modo, a fração Centro-Sul reproduziu o padrão do país, ou seja, perda relativa da participação de seus Centros 
Principais, ainda que continuem a incorporar a maior da parcela do produto. $\mathrm{O}$ mesmo não ocorre nas frações Norte e Nordeste, onde a participação dos Centros Principais era ligeiramente superior a das Demais Localidades em 1999, e em 2003 tornou-se equivalente, no caso da fração Nordeste, ou inferior, no caso da fração Norte ${ }^{2}$.

É importante ter em conta nesse tipo de análise não só o significado dos números relativos, mas também o dos números absolutos. Assim, conforme os dados da Tabela 1, um aumento de participação da ordem de 1\% em poucos anos, pode representar um acréscimo ao produto de muitos bilhões de reais. Entre 2001 e 2003, por exemplo, no Centro Sul, enquanto os Centros Principais perdem participação, as Demais Localidades incorporaram o impressionante ganho nominal de 117,7 bilhões de reais, enquanto as Localidades Intermediárias internalizaram cerca de 83,0 bilhões, bem mais que os 75,9 bilhões dos Grandes Centros. Mesmo no Nordeste o incremento dos valores absolutos nesses três anos foi considerável: 21,7 bilhões a favor dos grandes centros, 13,5 para as Localidades Intermediárias e 21,6 bilhões para as Demais Localidades.

\footnotetext{
${ }^{2}$ Em 1999, o PIB dos Centros Principais da fração Nordeste respondia por 39,99\% do PIB da fração e o dasDemais Localidades, 37,16\%. Já em 2003, o PIB dos Centros Principais declina para 38,6\% e o das Demais Localidades evolui para $38,17 \%$. Com relação à fração Norte, o PIB dos seus Centros Principais correspondeu a 38,94\% e o das Demais Localidades, 36,79\%; em 2003, o dos Centros Principais, 36,59\% e o das Demais Localidades, 38,5\% (Tabela 1).

Cadernos do Leste 
Tabela1: Produto Interno Bruto emReais) segundo Frações da Rede de localidades centrais do Brasil entre 1999 e 2003

\begin{tabular}{|c|c|c|c|c|c|c|c|c|}
\hline \multirow[b]{3}{*}{ Ano } & \multicolumn{8}{|c|}{ Fraçäo Centro-Sul } \\
\hline & \multicolumn{2}{|c|}{ Centros Principais } & \multicolumn{2}{|c|}{$\begin{array}{c}\text { Centros } \\
\text { Intermediários }\end{array}$} & \multicolumn{2}{|c|}{$\begin{array}{c}\text { Demais } \\
\text { Localidades }\end{array}$} & \multicolumn{2}{|l|}{ Total } \\
\hline & $\overline{\mathrm{N}}$ & $\%$ & $\bar{N}$ & $\%$ & $\overline{\mathbf{N}}$ & $\%$ & $\bar{N}$ & $\%$ \\
\hline 2003 & 520608571 & 41.49 & 323317830 & 25.77 & 410853716 & 32.74 & 1254780117 & $\overline{80.63}$ \\
\hline 2002 & 472102687 & 43.35 & 268633975 & 24.67 & 348209890 & 31.88 & 1088946552 & $\frac{0.000}{80.90}$ \\
\hline 2001 & 444735732 & 45.46 & 240307324 & 24.56 & 283231703 & 29.97 & 978274759 & 81.61 \\
\hline 2000 & 415788494 & 46.15 & 223401040 & 24.80 & 261696289 & 29.05 & 900885833 & 81.81 \\
\hline \multirow[t]{3}{*}{1909} & 366987794 & 45.97 & 193710946 & 24.27 & 237554782 & 29.76 & 788253522 & 81.97 \\
\hline & \multicolumn{8}{|c|}{ Fracao Nordeste } \\
\hline & \multicolumn{2}{|c|}{ Centros Principais } & \multicolumn{2}{|c|}{$\begin{array}{c}\text { Centros } \\
\text { Intermediários }\end{array}$} & \multicolumn{2}{|c|}{$\begin{array}{c}\text { Demais } \\
\text { Localidades }\end{array}$} & \multicolumn{2}{|l|}{ Total } \\
\hline \multicolumn{9}{|l|}{ Ano } \\
\hline 2003 & 82576133 & 38.60 & 49706059 & 23.23 & 81649907 & 38.17 & 213932099 & 13.75 \\
\hline 2002 & 68874450 & 37.89 & 41400232 & 22.77 & 71516691 & 30.34 & 181791373 & 13.51 \\
\hline 2001 & 60889743 & 38.73 & 36250324 & 23.06 & 60065504 & 38.21 & 157205571 & 13.11 \\
\hline 2000 & 56853210 & 39.51 & 32739595 & 22.71 & 54439266 & 37.77 & 144132071 & 13.09 \\
\hline \multirow[t]{3}{*}{1899} & 50830879 & 39.88 & 29324125 & 2296 & 47464957 & 37.16 & 127719961 & 13.12 \\
\hline & \multicolumn{8}{|c|}{ Fracalo Norte } \\
\hline & \multicolumn{2}{|c|}{ Centros Principais } & \multicolumn{2}{|c|}{$\begin{array}{c}\text { Centros } \\
\text { Intermediários }\end{array}$} & \multicolumn{2}{|c|}{$\begin{array}{c}\text { Demais } \\
\text { Localidades }\end{array}$} & \multicolumn{2}{|l|}{ Total } \\
\hline Ano & $\bar{N}$ & $\%$ & $\bar{N}$ & $\%$ & $\bar{N}$ & $\%$ & $\bar{N}$ & $\%$ \\
\hline 2003 & 32307003 & 36.94 & 21483824 & 24.56 & 33678792 & 38.50 & 87469619 & 5.62 \\
\hline 2002 & 28515803 & 37.87 & 18406638 & 24.45 & 28367321 & 37.68 & 75289860 & 5.59 \\
\hline 2001 & 24836792 & 39.26 & 15453776 & 24.43 & 22965295 & 36.31 & 63255863 & 5.28 \\
\hline 2000 & 22355728 & 39.75 & 13824683 & 24.58 & 20056598 & 35.66 & 56237019 & 5.11 \\
\hline \multirow[t]{3}{*}{1809} & 18642742 & 38.94 & 11617805 & 24.27 & 17611463 & 36.79 & 47872010 & 4.82 \\
\hline & \multicolumn{8}{|c|}{ Brast } \\
\hline & \multicolumn{2}{|c|}{ Centros Principais } & \multicolumn{2}{|c|}{$\begin{array}{c}\text { Centros } \\
\text { Intermediários }\end{array}$} & \multicolumn{2}{|c|}{$\begin{array}{c}\text { Demais } \\
\text { Localidades }\end{array}$} & \multicolumn{2}{|l|}{ Total } \\
\hline Ano & $\bar{N}$ & $\%$ & $\mathbf{N}$ & $\%$ & $\mathrm{~N}$ & $\%$ & $\mathbf{N}$ & $\%$ \\
\hline 2003 & 635491707 & 40.84 & 304507713 & 25.35 & 526182415 & 33.81 & 1556181835 & 100.0 \\
\hline 2002 & 569493040 & 42.31 & 328440843 & 24.40 & 448003902 & 33.29 & 1346027785 & 100.0 \\
\hline 2001 & 530462267 & 44.25 & 292011424 & 24.36 & 376262502 & 31.39 & 1198736193 & 100.0 \\
\hline 2000 & 495097432 & 44.96 & 269965328 & 24.51 & 336192163 & 30.53 & 1101254923 & 100.0 \\
\hline 1999 & 436561415 & 44.83 & 234652876 & 24.10 & 302631202 & 31.08 & 973845493 & 100.0 \\
\hline
\end{tabular}

Fonte: IBGE: Banco de Informações Municipais (Tabulações especiais Leste).

A Tabela 2 traz a distribuição percentual do PIB, em termos de valor adicionado, pelos setores econômicos dos centros urbanos segundo as frações da RLC, entre 1999 e 2003. Esses dados permitem afirmar que o setor de serviço contribui com a maior parte do PIB, seguido pelo setor industrial e, por último, pelo setor agropecuário. Essa regularidade é observada tanto para o país como um todo, quanto para as frações da $R L C$, bem como entre as localidades que conformam a hierarquia urbana da rede. É interessante notar que, em relação ao total do país, cresceu a participação no PIB dos setores agropecuário e industrial: o primeiro representava 7,36\%, em 1999, e, em 2003, esse percentual elevouse para 9,8\% e o segundo passou de 35,6\% para 39,9\%, no mesmo período. Esse crescimento se fez também presente em todas as três frações: na fração Centro-Sul, o setor agropecuário cresceu 2,6

Cadernos do Leste

Artigos Cientificos

Belo Horizonte, Jan.-Dez. Vol.9, n9, 2009 
pontos percentuais e o setor industrial, 3,22\%; na fração Nordeste, o primeiro setor cresceu 1,41\% e o segundo, 3,78\%; na fração Norte, $1,44 \%$ e 5,89\%, respectivamente.

Tabela 2: Brasil: 2003. Distribuição Percentual do Valor Adicionado ao Produto Interno Bruto pelos Setores Econômicos. Hierarquia Urbana segundo Frações da Rede de localidades centrais- 1999 a $2003^{3}$.

\begin{tabular}{|c|c|c|c|c|c|c|c|c|c|c|c|}
\hline & \multicolumn{11}{|c|}{ Fração Centro-Sul } \\
\hline & \multicolumn{2}{|l|}{ Centros Principais } & \multicolumn{3}{|c|}{ Centros Intermediánios } & \multicolumn{3}{|c|}{ Demais Localidades } & \multicolumn{3}{|c|}{ Total } \\
\hline Ano & Agropecuária Industria & Servico & \begin{tabular}{|l|} 
Agropecuária| \\
\end{tabular} & \begin{tabular}{l|} 
Industria \\
\end{tabular} & Servico & Agropecuánia & Industria & Servico & Agropecuária & Industria & Servico \\
\hline 20,03 & 37.85 & 56.59 & 3.37 & 50.27 & 50.27 & 25.53 & 36.17 & 34.94 & 9.41 & 40.50 & 44.86 \\
\hline 20002 & 35.40 & 58.87 & 3.37 & 47.08 & 47.08 & 23.48 & 36.17 & 37.32 & 8.52 & 38.53 & 47.90 \\
\hline 2001 & 35.78 & 57.00 & 2.96 & 45.24 & 45.24 & 21.30 & 35.63 & 38.97 & 728 & 38.06 & 48.09 \\
\hline 2000 & 36.04 & 55.66 & 2.26 & 44.85 & 44.85 & 18.10 & 36.04 & 40.57 & 6.26 & 38.22 & 48.29 \\
\hline \multirow[t]{3}{*}{1989} & 34.82 & 58.11 & 2.63 & 41.30 & 41.30 & 20.21 & 34.08 & 42.01 & 6.81 & 36.18 & 50.65 \\
\hline & \multicolumn{11}{|c|}{ Frafao Nordeste } \\
\hline & \multicolumn{2}{|l|}{ Centros Principais } & \multicolumn{3}{|c|}{ Centros Intermediários } & \multicolumn{3}{|c|}{ Demais Localidades } & \multicolumn{3}{|c|}{ Total } \\
\hline Ano & Agropecuária Industria & Servico & \begin{tabular}{|l|} 
Agropecuária \\
\end{tabular} & Industria & Servico & Agropecuánia & Industria & Servico & Agropecuária & Industria & Servico \\
\hline 2003 & 46.55 & 42.82 & 4.27 & 37.98 & 37.99 & 21.96 & 26.88 & 49.67 & 9.64 & 37.05 & 46.66 \\
\hline 2002 & 42.37 & 47.09 & 4.59 & 36.23 & 36.23 & 21.59 & 25.86 & 50.74 & 9.81 & 34.47 & 49.36 \\
\hline 2001 & 41.66 & 46.26 & 3.63 & 35.40 & 35.40 & 19.26 & 25.35 & 53.75 & 8.47 & 33.99 & 50.12 \\
\hline 2000 & 41.78 & 46,42 & 3.51 & 33.31 & 33.31 & 20.30 & 23.12 & 54.41 & 8.74 & 32.81 & 50.91 \\
\hline 1980 & 41.26 & 48.17 & 3.37 & 35.34 & 35.34 & 19.26 & 23.43 & 55.30 & 8.23 & 33.27 & 51.78 \\
\hline & \multicolumn{11}{|c|}{ FraçáoNorte } \\
\hline & \multicolumn{2}{|l|}{ Centros Principais } & \multicolumn{3}{|c|}{ Centros Intermediários } & \multicolumn{3}{|c|}{ Demais Localidades } & \multicolumn{3}{|c|}{ Total } \\
\hline Ano & Apropecuária Industria & Servico & Agropecuária & Industria & Servico & Aqropecuária & ndustria & Servico & Aqropecuária & Industria & Servico \\
\hline$\overline{2003}$ & 57.33 & 31.48 & 9.22 & 28.87 & 28.87 & \begin{tabular}{|c|}
34.63 \\
\end{tabular} & 25.86 & 36.29 & 15.73 & 38.26 & $39 . \overline{106}$ \\
\hline 2002 & 57.10 & 31.60 & 8.41 & 28.06 & 28.06 & 35.63 & 24.46 & 37.18 & 15.65 & 37.70 & 40.00 \\
\hline 2001 & 55.21 & 33.54 & 6.77 & 28.51 & 28.51 & 32.24 & 25.54 & 39.23 & $13.4 \mathrm{Q}$ & 37.91 & 41.68 \\
\hline 2000 & 51.44 & 38.11 & 7.16 & 26.05 & 26.05 & 32.41 & 22.30 & 41.85 & 13.46 & 34.81 & 44.97 \\
\hline \multirow[t]{3}{*}{1989} & 50.00 & 40.70 & 8.09 & 2276 & 22.76 & 33.10 & 20.05 & 43.92 & 14.29 & 32.37 & 47.45 \\
\hline & \multicolumn{11}{|c|}{ Brasil } \\
\hline & \multicolumn{2}{|l|}{ Centros Principais } & \multicolumn{3}{|c|}{ Centros Intermediários } & \multicolumn{3}{|c|}{ Demais Localidades } & \multicolumn{3}{|c|}{ Total } \\
\hline Ano & \begin{tabular}{|l|l|} 
Agropecuária Industria \\
\end{tabular} & Servico & Agropecuária & Industria & Servico & Agropecuária & Industria & Servico & Agropecuária & Industria & Servico \\
\hline 2003 & 39.97 & 53.53 & 3.80 & 47.55 & 47.55 & 25.56 & 34.07 & 37.32 & 9.80 & 39.90 & 44.78 \\
\hline 20.02 & 37.33 & 56.08 & 3.81 & 44.65 & 44.65 & 23.85 & 33.78 & 39.46 & 9.10 & 37.93 & 47.65 \\
\hline 2001 & 37.30 & 54.67 & 3.24 & 43.13 & 43.13 & 21.64 & 33.37 & 41.34 & 7.76 & 37.52 & 48.02 \\
\hline 2000 & 37.39 & 53.80 & 2.66 & 42.48 & 42.48 & 20.09 & 33.13 & 42.90 & 6.85 & 37.34 & 48.47 \\
\hline 1989 & 36.22 & 56.21 & 2.90 & 39.64 & 39.64 & 20.81 & 31.60 & 44.22 & 7.36 & 35.61 & 50.64 \\
\hline
\end{tabular}

Fonte: IBGE. Banco de Informações Municipais (Tabulações especiais Leste).

${ }^{3} \mathrm{O}$ fato de os percentuaisnãosomarem $100 \%$ se deve ao pela ausência do valor adicionado do fatorImposto, que tambémé computado conforme a definição do PIB.

Cadernos do Leste

Artigos Cientificos

Belo Horizonte, Jan.-Dez. Vol.9, nº 9, 2009 
Cabe ressaltar ainda que o peso relativo do setor agropecuário na fração Norte éconsideravelmente maior do que nas outras frações. Nas frações Centro-Sul e Nordeste, essa participação variou de 6,8\% (fração Centro-Sul em 1999) até 9,64\% (fração Nordeste em 2003); na Norte, de 14,29\% até 15,73\%, ou seja, quase o dobro dos percentuais das outras frações.

A distribuição percentual do PIB pelos setores econômicos dos centros urbanosbrasileiros confirma a tese de que quanto maior o grau de centralidade de uma dada localidade, maior a participação do produto do setor de serviços na soma total do produto final.

Como contraponto pode-se correlacionar dois setores territorialmente distintos. Pelosdados da Tabela 2 verifica-se que enquanto o grau de participação do setor agropecuário representava, em média, 22\% do total do PIB do conjunto das Demais Localidades entre 1999 e 2003, nos Centros Principais, a média desses percentuais cai para 0,42\% e nos Centros Intermediários ela gira em torno dos $3,3 \%$.

Por outro lado, ao se analisar o grau de participação do setor de serviços dos Centros Principais, percebe-se que há uma clara hierarquia entre esses centros em termos de valores do PIB. Os da fração Centro-Sul possuem o maior grau de centralidade, seguidos pelos da fração Nordeste e Norte, nessa ordem. Nos primeiros, o percentual de participação do setor de serviços esteve sempre acima daquele obtido para o país como um todo. Nos dois outros esses percentuais mantiveram-se abaixo do nacional.

Em relação ao setor industrial, ocorre justamente o contrário, são os Centros Principaisda fração Norte que apresentam os maiores percentuais de participação, seguidos pelos centros da Fração Nordeste e, por último, pelos da fração Centro-Sul. Algo semelhante ocorre com a participação do setor agropecuário em relação aos Centros Intermediários das frações da RLC, ou seja, quando comparados entre si, são os Centros Intermediários da fração norte os que apresentam os maiores percentuais de participação do referido setor no PIB desses centros, logo após vêm os Centros Intermediários da fração Nordeste seguidos pelos da Fração Centro-Sul (Tabela 2).

A distribuição espacial das taxas de crescimento do PIB municipal e a do valoradicionado pelos setores econômicos, entre 1999 e 2003, estão ilustrados nas figuras em sequência.

As informações sobre a evolução municipal do PIB indicam que foram raros os casosde crescimento negativo e, ao contrário, não foram poucas as localidades que apresentaram taxas superiores às nacionais, tal como pode ser percebido na Figura 2. Com relação aos valores do PIB e aos valores adicionados pelos setores agropecuário e industrial nos anos 1999 e 2003, a análise da Figura 4 indica que a distribuição espacial das atividades industriais segue o padrão ditado pela 
distribuição espacial do conjunto total das atividades econômicas pelo território brasileiro. Nota-se, ainda, que foi visível o aumento da atividade do setor agropecuário durante o período em, principalmente, todas as frações.

Figura 1: Brasil: 1999/2003. Taxa de Crescimento do Produto Interno Bruto dos Municípios Brasileiros

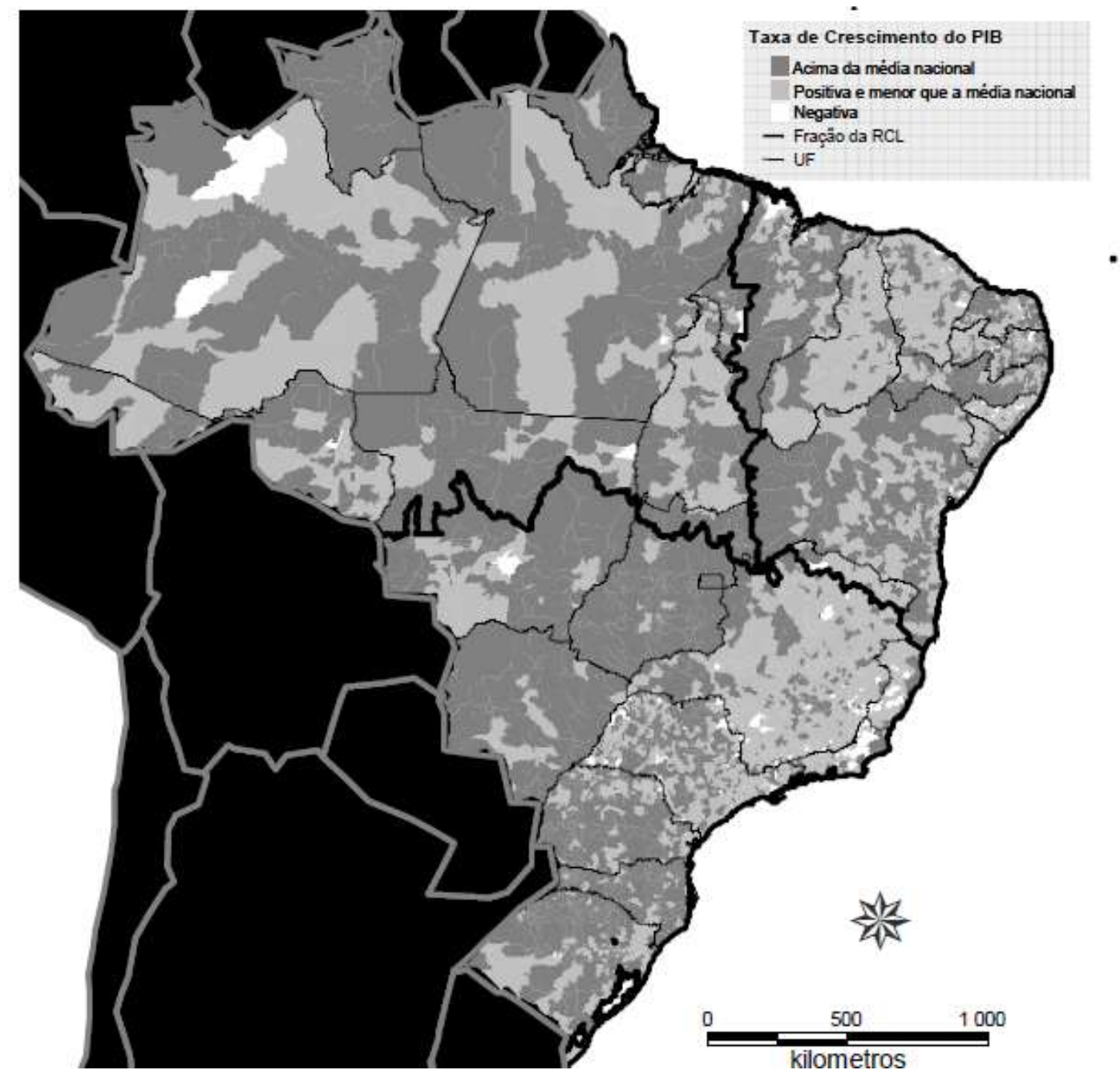

Fonte: IBGE. Banco de Informações Municipais e Malha Digital Municipal 2000.

Cadernos do Leste

Artigos Cientificos

Belo Horizonte, Jan.-Dez. Vol.9, nº 2009 
Figura 2: Brasil: 1999/2003. Produto Interno Bruto dos Municípios Brasileiros. Valor Adicionado pelos Setores Agropecuário e Industriais - 1999/2003
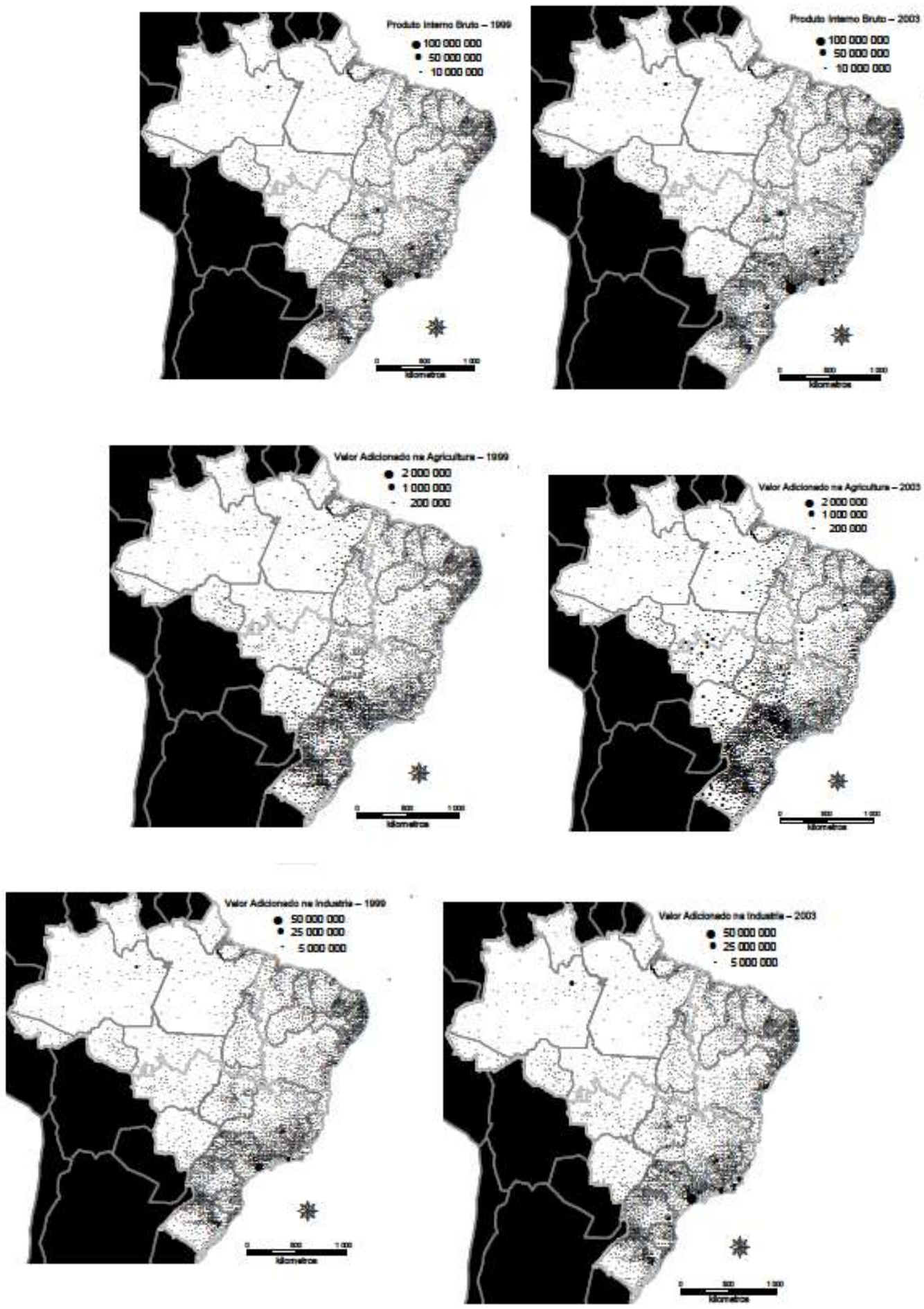

Fonte: IBGE. Banco de Informações Municipais e Malha Digital Municipal 2000.

Cadernos do Leste 


\section{3- A DECOMPOSIÇÃO DO CRESCIMENTO POPULACIONAL NA REDE DE LOCALIDADES CENTRAISENTRE 1995 E 2000}

O crescimento populacional pode ser decomposto em dois componentes básicos, um relacionado ao comportamento das variáveis mortalidade e fecundidade, que resultam no crescimento natural ou vegetativo de uma dada população e outro, relacionado aos movimentos de entrada e saída de população (imigração e emigração em determinada área). Tomado como base os dados de entrada e saída de migrantes, em um dado período, eadicionando seus respectivos efeitos indiretos (Garcia e Miranda-Rigeiro, 2005; Garcia e Carvalho, 2005), pode-se se obter estimativas da população esperada fechada ao final de um dado período para uma localidade e, por conseguinte, estimar sua taxa de crescimento natural. $O$ resultado da diferença entre a taxa de crescimento total e natural pode ser interpretado como a taxa de migração líquida que, por sua vez, também pode ser decomposta em taxa de emigração e taxa de imigração (Garcia e Soares-filho, 2005; Preston, Heuveline e Guillot, 2000).

Com base nos dados sobre a migração municipal proveniente dos microdados doCenso Demográfico de 2000 e seguindo os procedimentos resumidos acima, foi possível estimar as taxas anuais de crescimento vegetativo, bem como as taxas anuais de emigração, imigração e taxas anuais de migração líquida dos centros urbanos das frações da RLC, para a segunda metade da década de 90, tal como pode ser observado na Tabela 3. Assumindo-se que o saldo migratório internacional durante esse período foi pequeno, tomou-se o crescimento observado como proxy do crescimento vegetativo do país como um verificou-se que o Brasil cresceu entre 1995 e 2000 a taxa média de, aproximadamente, $1,7 \%$ ao ano, mas esse crescimento não foi uniformemente distribuído ao longo do território nacional.

Houve considerável variação do crescimento vegetativo, expresso em termos de taxasanuais, entre as frações da RLC. A fração Norte apresentou taxas de crescimento muito superiores a nacional $(2,83)$, ao passo que a fração Nordeste cresceu à taxa muito próxima a do Brasil $(1,69)$ e a fração Centro-Sul, à taxa inferior à média nacional $(1,57)$. Análise semelhante pode ser feita em relação aos tipos de localidades que compõem as frações da RLC. Entretanto, outra regularidade empírica pode também ser constatada: os Centros Principais e intermediários são os que apresentaram maiores taxas de crescimento.

A fração Centro-Sul apresentou uma taxa líquida anual de migração de $0,14 \%$, contra0,11\% da fração Norte enquanto a fração Nordeste destacou-se como a grande perdedora de população relativa com uma taxa líquida negativa de $0,33 \%$, aproximadamente. Não obstante, a taxa total de 
movimentos migratórios entre as frações da RLC ultrapassa 1,0\% do total da população na fração Norte, $0,9 \%$, na fração Nordeste e $0,4 \%$ na fração Centro-Sul. Outroaspecto notável a ser comentado é que foram os Centros Intermediários os principais responsáveis pela retenção de população, internalizando, para o país como um todo, taxas líquidas positivas da ordem de $0,42 \%$ ao ano, contra apenas 0,05\%, observadas nos Centros Principais. Mais especificamente, foram os Centros Intermediários da fração Centro-Sul os que mais retiveram população relativa, com taxa anual de 0,58\%. E, ao contrário, as DemaisLocalidades da fração Nordeste foram as que mais perderam, com taxa negativa de $0,59 \%$.

A distribuição espacial das taxas anuais de crescimento vegetativo e das taxaslíquidas anuais de migração dos municípios brasileiros, para o período 1995/2000, está ilustrada, respectivamente, nas Figuras 3 e 4, onde se destacam, ainda, os limites das frações da RLC e das unidades da federação.

Tabela 3: Brasil: 2000. Indicadores demográficos selecionados. Hierarquia Urbana segundo

Frações da Rede de localidades centrais - 1995/2000.

\begin{tabular}{|c|c|c|c|c|}
\hline \multicolumn{5}{|c|}{ Fração Centro-Sul } \\
\hline Indicadores demográficos & $\begin{array}{c}\text { Centros } \\
\text { Principais }\end{array}$ & \begin{tabular}{c|} 
Centros \\
Intermediários
\end{tabular} & $\begin{array}{c}\text { Demais } \\
\text { Localidades }\end{array}$ & Total \\
\hline Taxa de crescimento vegetativo - $1985 / 2000(\%)$ & 1.77 & 1.76 & 1.26 & 1.57 \\
\hline Taxa de Imigração a.a. - $1995 / 2000(\%)$ & 0.98 & 1.78 & 0.99 & 0.30 \\
\hline $\begin{array}{l}\text { Taxa de Emigração a.a. - } 1995 / 2000(\%) \\
\text { Taxa de Liquida de Migração a.a. - } 1995 / 2000(\%)\end{array}$ & $\begin{array}{l}0.97 \\
0.01\end{array}$ & $\begin{array}{l}1.17 \\
0.58\end{array}$ & $\begin{array}{r}1.00 \\
-0.01\end{array}$ & $\begin{array}{l}0.17 \\
0.14\end{array}$ \\
\hline \multicolumn{5}{|c|}{ Fraçäo Nordeste } \\
\hline Indicadores demográficos & $\begin{array}{c}\text { Centros } \\
\text { Principais }\end{array}$ & \begin{tabular}{|c|} 
Centros \\
Intermediários
\end{tabular} & $\begin{array}{c}\text { Demais } \\
\text { Localidades }\end{array}$ & Total \\
\hline Taxa de crescimento vegetativo - $1995 / 2000(\%)$ & 1.88 & 2.04 & 1.53 & 1.69 \\
\hline Taxa de Imigração a.a. - $1995 / 2000(\%)$ & 1.00 & 1.55 & 0.61 & 0.30 \\
\hline Taxa de Emigração a.a. - 1995/2000 (\%) & 0.85 & 1.54 & 1.20 & 0.63 \\
\hline Taxa de Liquida de Migração a.a. - $1985 / 2000$ (\%) & 0.15 & 0.01 & -0.59 & -0.33 \\
\hline \multicolumn{5}{|c|}{ Fraçäo Norte } \\
\hline Indicadores demográficos & $\begin{array}{l}\text { Centros } \\
\text { Principais }\end{array}$ & \begin{tabular}{c|} 
Centros \\
Intermediánios
\end{tabular} & $\begin{array}{c}\text { Demais } \\
\text { Localidades }\end{array}$ & Total \\
\hline Taxa de crescimento vegetativo - $1985 / 2000(\%)$ & 2.91 & 3.15 & 2.63 & 2.83 \\
\hline Taxa de Imigração a.a. - 1995/2000 (\%) & 1.54 & 2.13 & 1.36 & 0.68 \\
\hline Taxa de Emigrạ̧ão a.a. - $1995 / 2000(\%)$ & 1.19 & 1.82 & 1.45 & 0.56 \\
\hline Taxa de Liquida de Migração a.a. - 1985/2000 (\%) & 0.35 & 0.31 & -0.09 & 0.11 \\
\hline \multicolumn{5}{|c|}{ Brasil } \\
\hline Indicadores demográficos & $\begin{array}{c}\text { Centros } \\
\text { Principais }\end{array}$ & \begin{tabular}{c|} 
Centros \\
Intermediánios
\end{tabular} & $\begin{array}{c}\text { Demais } \\
\text { Localidades }\end{array}$ & Total \\
\hline Taxa de crescimento vegetativo - $1985 / 2000(\%)$ & 1.86 & 1.96 & 1.49 & 1.71 \\
\hline Taxa de Imigraçäo a.a. - 1995/2000 (\%) & 0.93 & 1.65 & 0.78 & 0.00 \\
\hline Taxa de Emigração a.a. - 1985/2000 (\%) & 0.88 & 1.22 & 1.00 & 0.00 \\
\hline Taxa de Liquida de Migraçäo a.a. - $1985 / 2000$ (\%) & 0.05 & 0.42 & -0.24 & 0.00 \\
\hline
\end{tabular}

Fonte: IBGE. Censo Demográfico de 2000 e 1991 (Tabulações especiais Leste).

Uma rápida análise da Figura 3 revela que a maior parte do território nacionalapresentou taxas positivas de crescimento vegetativo. Chama atenção, ainda, as taxas acima da média nacional 
presentes nos municípios da Região Amazônica, dos municípios fronteiriços e Demais Localidades da fração Nordeste. Grosso modo, o território nacional apresenta-se, no que diz respeito à componente vegetativa do crescimento populacional, constituído de localidades cujas taxas brutas de natalidade são superiores as das brutas de mortalidade, exceto em áreas demograficamente vazias ou despovoadas de jovens adultos de ambos os sexos.

A análise da distribuição espacial das taxas líquidas anuais de migração indica umoutro cenário para a composição territorial brasileira (Fig. 4). Com relação à espacialidade dessas taxas o Brasil parece mais um arquipélago de localidades retentoras de população cercado de um mar de localidades expulsoras. Essas informações tendem a corroborar a continuidade do aspecto altamente heterogêneo do processo de crescimento populacional brasileiro. Processo esse que estabelece grande relação com a espacialidade das atividades produtivas no país, tal como se pode ver nos mapas de distribuição do PIB no item anterior.

Cadernos do Leste 
Figura 3: Brasil: 2000. Taxa de Crescimento Vegetativo dos Municípios Brasileiros $1995 / 2000$

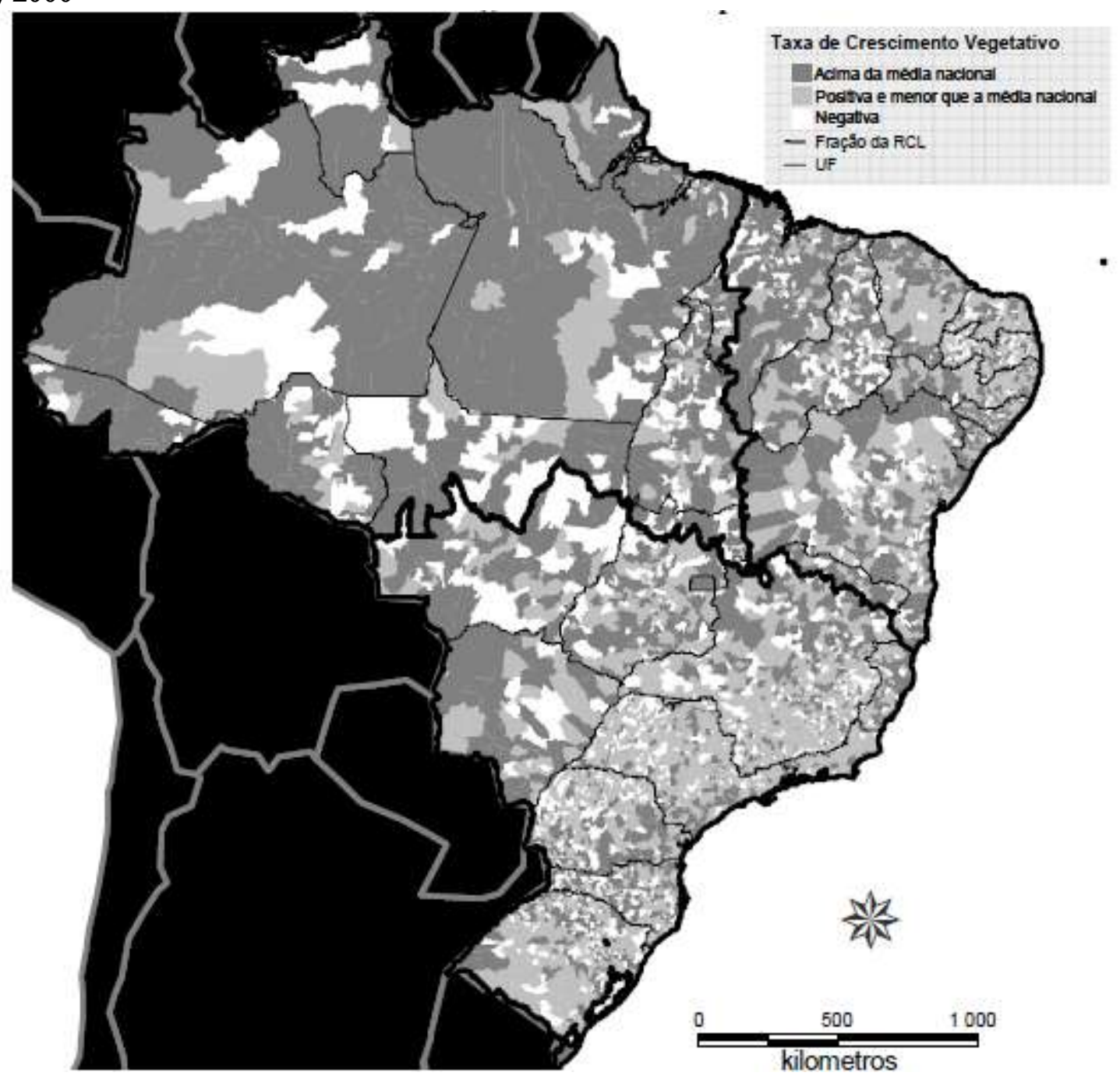

Fonte: IBGE. Banco de Informações Municipais e Malha Digital Municipal 2000 (Tabulações especiais Leste).

\section{Estimativas do Crescimento Populacional dos Centros Urbanos da Rede de Localidades} Centrais a partir de 2005

Para a finalização dessa análise apresenta-se a seguir um exercício de projeçãopopulacional, cobrindo o período 2005-2025, aplicado ao recorte espacial aqui adotado. Dadas as inferências empíricas até aqui expostas, a pergunta que se coloca é se o quadro de tendências da dinâmica demográfica poderá se alterar significativamente nos próximos 20 anos, mesmo considerando as impossibilidade de introduzir muita precisão em uma questão dessa natureza.

Cadernos do Leste 
Figura 4: Brasil: 2000. Taxa de Líquida de Migração dos Municípios Brasileiros $1995 / 2000$

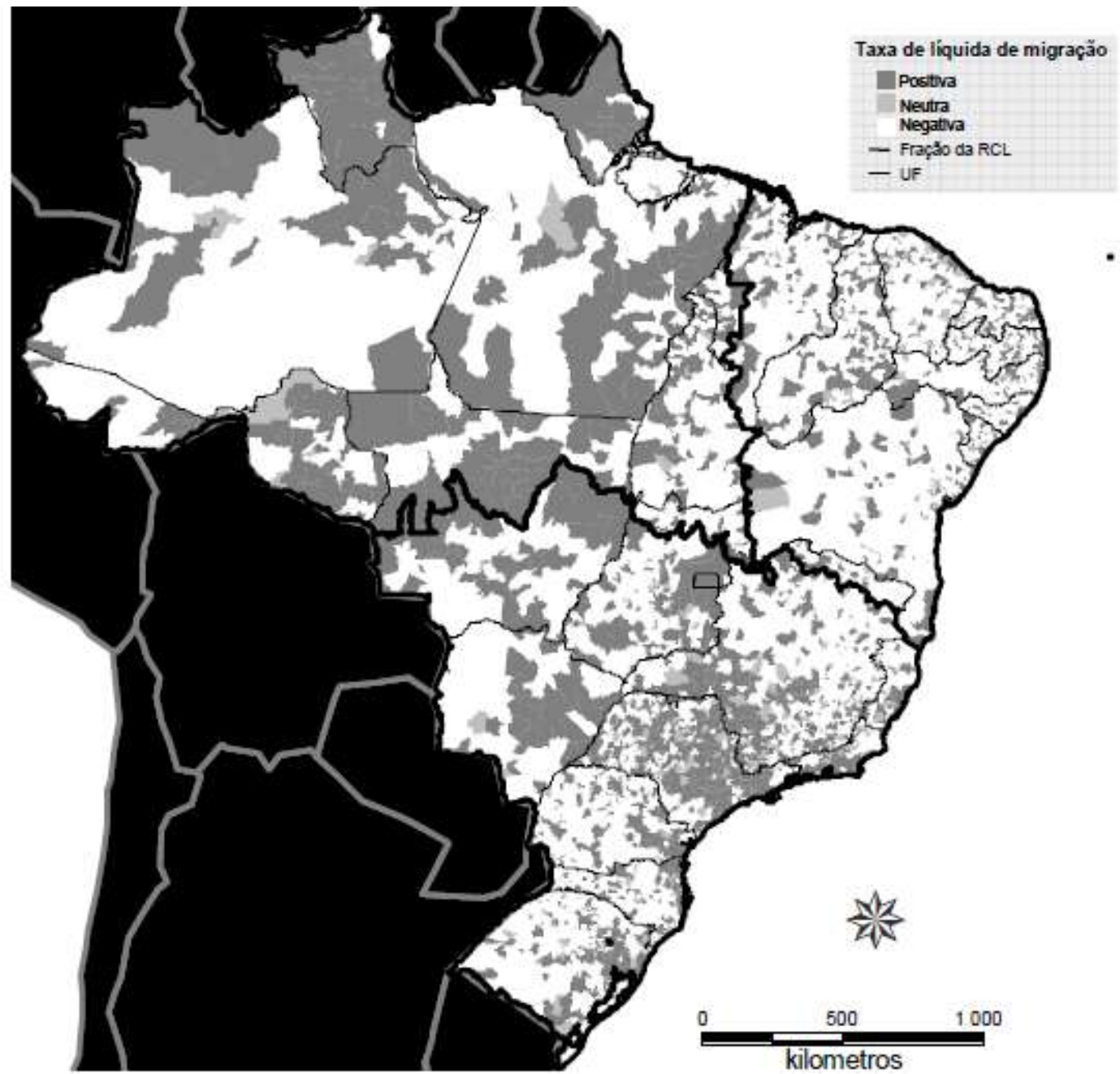

Fonte: IBGE. Banco de Informações Municipais e Malha Digital Municipal 2000 (Tabulações especiais Leste).

O IBGE, através de sua diretoria de pesquisa e da coordenação de população eindicadores sociais (IBGE, 2004), disponibiliza estimativas anuais, por sexo e idade, da população brasileira, entre 1980 e 2050, bem como a metodologia para a estimação da população municipal, tendo como base a projeção do país como um todo, através do métodoconhecido por AiBi modificado. O instituto não fornece, infelizmente, a série completa de estimativas da população municipal para todo o período, limitando-se a divulgá-las anualmente. Essas informações são, contudo, de extrema importância quando se quer analisar o crescimento populacional dos centros urbanos nacionais. Nesse sentido, as estimativas da população municipal utilizadas, nesse trabalho, para a análise da tendência do crescimento populacional das localidades da $R L C$, foram obtidas através da aplicação 
da mesma metodologia empregada pelo IBGE (AiBi modificado), com base na projeção anual da população brasileira, também divulgada pelo Instituto.

Com base nas estimativas anuais da população brasileira entre 1980 e 2050 e atravésdo método $A$ iBi modificado, proposto pelo IBGE, pôde-se estimar evolução quinquenal da população residente nos centros urbanos da RLC, entre 2005 e 2025. Os dados da Tabela 4 revelam que, em termos da distribuição percentual da população entre as frações da $R L C$, não são esperadas grandes alterações durante esse período, ou seja: a fração Centro-Sul continuará mantendo os mesmos 63\% da população residente no país, a fração nordeste, perto de $28 \%$ e a fração Norte, $9 \%$.

Cadernos do Leste 
Tabela 4: Brasil: 2045. População Residente Estimada. Hierarquia Urbana segundo Frações da Rede de localidades centrais - 2005/2025

Fração Centro-Sul

\begin{tabular}{|c|c|c|c|c|c|c|c|c|}
\hline \multirow[b]{2}{*}{ Ano } & \multicolumn{2}{|c|}{ Centros Principais } & \multicolumn{2}{|c|}{$\begin{array}{c}\text { Centros } \\
\text { Intermediários }\end{array}$} & \multicolumn{2}{|c|}{$\begin{array}{c}\text { Demais } \\
\text { Localidades }\end{array}$} & \multicolumn{2}{|l|}{ Total } \\
\hline & $\mathrm{N}$ & $\%$ & $\mathrm{~N}$ & $\%$ & $\mathrm{~N}$ & $\%$ & $\mathrm{~N}$ & $\%$ \\
\hline 2005 & 44667516 & 38.28 & 28382377 & 24.32 & 43639324 & 37.40 & 116689218 & 63.35 \\
\hline 2015 & 50279387 & 38.10 & 33147592 & 25.12 & 48547010 & 36.79 & 131973989 & 63.31 \\
\hline \multirow[t]{3}{*}{2025} & 54995049 & 37.98 & \begin{tabular}{|l|}
37151807 \\
\end{tabular} & 25.65 & 52670944 & 36.37 & 144817800 & 63.27 \\
\hline & \multicolumn{8}{|c|}{ Fraçáo Nordeste } \\
\hline & \multicolumn{2}{|c|}{ Centros Principais } & \multicolumn{2}{|c|}{$\begin{array}{c}\text { Centros } \\
\text { Intermediários }\end{array}$} & \multicolumn{2}{|c|}{$\begin{array}{c}\text { Demais } \\
\text { Localidades }\end{array}$} & \multicolumn{2}{|l|}{ Total } \\
\hline Ano & $\mathrm{N}$ & $\%$ & $\mathrm{~N}$ & $\%$ & \begin{tabular}{l|l}
$\mathrm{N}$ \\
\end{tabular} & $\%$ & $\mathrm{~N}$ & $\%$ \\
\hline 2005 & 10208076 & 19.81 & 9786187| & 18.99 & 31541442 & 61.20 & 51535705 & 27.98 \\
\hline 2015 & 11667959 & 20.11 & 11285446 & 19.45 & 35062597 & 60.44 & 58016002 & 27.83 \\
\hline \multirow[t]{3}{*}{2025} & 12894700 & 20.32 & 12545276 & 19.77 & 38021428 & 59.91 & 63461403 & 27.73 \\
\hline & \multicolumn{8}{|c|}{ Fraçáo Norte } \\
\hline & \multicolumn{2}{|c|}{ Centros Principais } & \multicolumn{2}{|c|}{$\begin{array}{c}\text { Centros } \\
\text { Intermediários }\end{array}$} & \multicolumn{2}{|c|}{$\begin{array}{c}\text { Demais } \\
\text { Localidades }\end{array}$} & \multicolumn{2}{|l|}{ Total } \\
\hline Ano & $\mathrm{N}$ & $\%$ & $\bar{N}$ & $\%$ & $\overline{\mathrm{N}}$ & $\%$ & $\bar{N}$ & $\%$ \\
\hline 2005 & 3667942 & 22.98 & 4455159 & 27.92 & 7836239 & 49.10 & 15959341 & 8.66 \\
\hline 2015 & 4456261 & \begin{tabular}{|l|}
24.12 \\
\end{tabular} & 5312999 & 28.75 & 8708784 & 47.13 & 18478044 & 8.86 \\
\hline \multirow[t]{3}{*}{2025} & 5118687 & 24.85 & 6033843 & 29.30 & 9441984 & 45.85 & 20594514 & 9.00 \\
\hline & \multicolumn{8}{|c|}{ Brasil } \\
\hline & \multicolumn{2}{|c|}{ Centros Principais } & \multicolumn{2}{|c|}{$\begin{array}{c}\text { Centros } \\
\text { Intermediários }\end{array}$} & \multicolumn{2}{|c|}{$\begin{array}{c}\text { Demais } \\
\text { Localidades }\end{array}$} & \multicolumn{2}{|l|}{ Total } \\
\hline Ano & $\mathrm{N}$ & $\%$ & $\mathrm{~N}$ & $\%$ & $\mathrm{~N}$ & $\%$ & $\mathrm{~N}$ & $\%$ \\
\hline 2005 & 58543534 & 31.78 & 42623724 & 23.14 & 83017006 & 45.07 & 184186269 & 100.0 \\
\hline 2015 & 66403607 & 31.85 & 49746037 & 23.86 & 92318391 & 44.28 & 208470050 & 100.0 \\
\hline 2025 & 73008436 & 31.90 & 55730926 & 24.35 & 100134356 & 43.75 & 228875742 & 100.0 \\
\hline
\end{tabular}

Ao analisar esses percentuais em relação aos centros urbanos, os resultados tendem aconfirmar a continuidade processo de esvaziamento das localidades menos dinâmicas do país em favor dos Centros Intermediários. Tudo indica que esse processo será relativamente mais intenso na fração Norte, uma vez que o percentual da participação das Demais Localidades da fração cairá de 49,10\% para 45,9\%, enquanto os Centros Principais tenderão a aumentar seu grau de participação passando dos atuais 22,98\% para 24,85\% ao final do período. O mesmo não ocorrerá em relação aos Centros Principais da fração Centro-Sul, que de acordo com as atuais tendências, perderão participação relativa, declinando dos 38,28\% a 37,98\% em 2025. Paralelamente, ampliamse as participações dos Centros Principais das demais frações, o que acaba por fazer aumentar no cômputo geral a participação nacional desses centros de 31,78\% para 31,90\% em 2025. Com respeito aos Centros Intermediários, estima-se que haverá aumento de sua participação relativa ao longo dos próximos 20 anos em todas as três frações da $R L C$.

Cadernos do Leste 
Por fim, as figuras 5 e 6 ilustram a distribuição espacial da população brasileira nosanos de 2005, 2025.

Figura 5: Brasil: 2005. População Estimada Residente nos Municípios Brasileiros

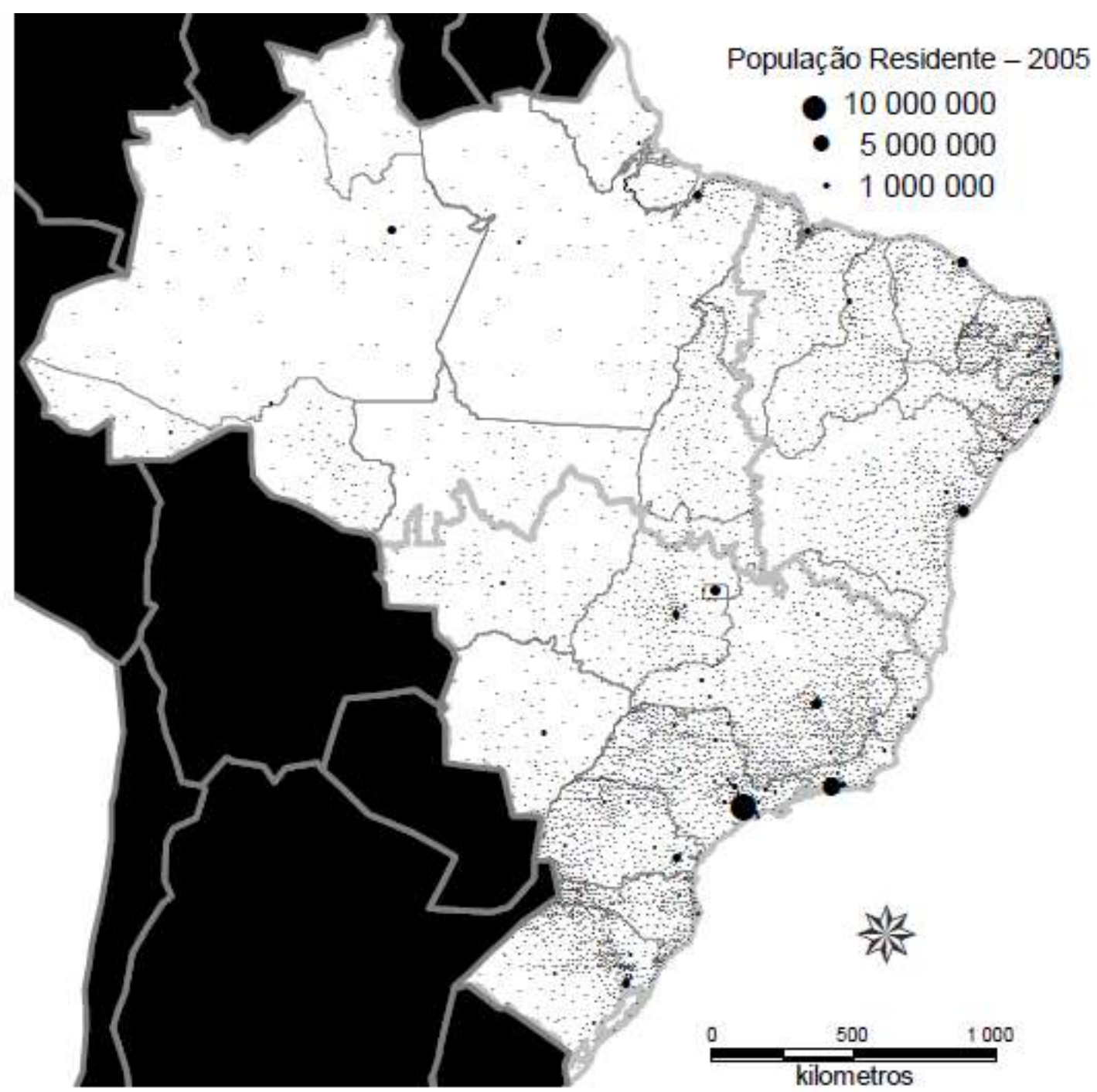

Fonte: IBGE. Projeção da População do Brasil por Sexo e Idade para o Período 1980 -2050 - Revisão 2004 e Malha Digital Municipal 2000.

Cadernos do Leste 
Figura 6: Brasil: 2025. População Estimada Residente nos Municípios Brasileiros

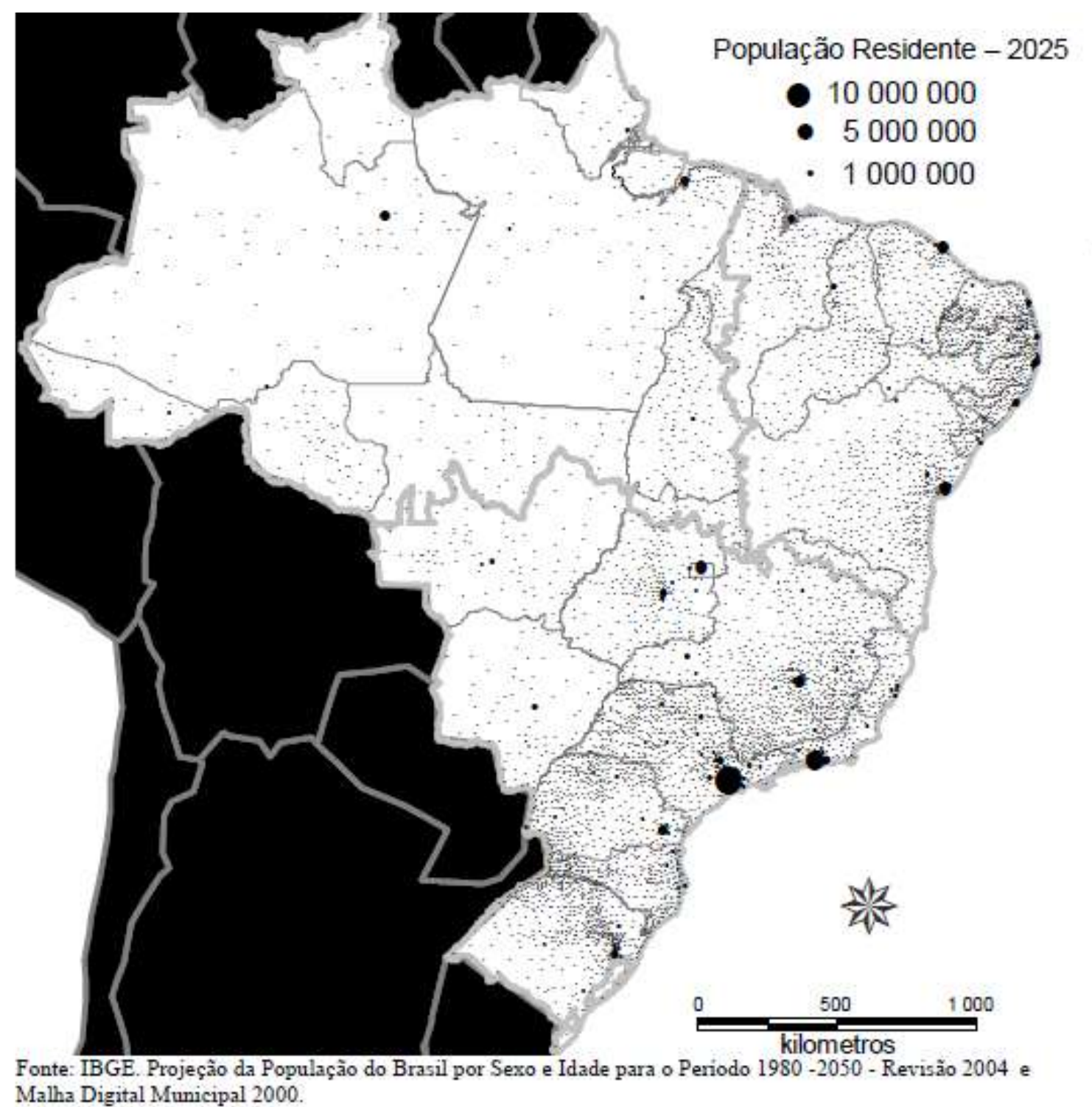

\section{CONSIDERAÇÕES FINAIS}

Esse estudo, que é parte de um conjunto maior de reflexões e pesquisas, não concluiefetivamente se os determinantes do crescimento populacional brasileiro ou da migração nos próximos 20 anos serão o resultado basicamente da reestruturação dada pelas novas territorialidades nas quais a produção de riqueza se dará com mais intensidade. Há outros fatores em jogo, como os já referidos na introdução e outros de cunho institucional. Por exemplo, pode-se ter um estoque de imensas áreaspassíveis de ocupação, mas com impedimentos de cunho legal e administrativo. Da mesma forma, no âmbito estrito da população a carência ou o custo da mão-de-

Cadernos do Leste

Artigos Cientificos

Belo Horizonte, Jan.-Dez. Vol.9, n9, 2009 
obra disponível pode inviabilizar projetos econômicos meritórios, com forte capacidade de transmitir efeitos multiplicadores no espaço geográfico.

Contudo, ainda assim as evidências permitem apontar algumas tendências que vinculamclaramente economia, demografia e espaço, mesmo sem detalhar as idiossincrasias que a geografia física impõe à esses espaços, algo que poderia incorporar-se aos mapas aqui apresentados (como por exemplo, a forma e os limites da ocupação do cerrado, as barreiras à ocupação nos baixios da floresta equatorial amazônica, a semiaridez do Nordeste ou o ciclo das águas no Pantanal Matogrossense).

Resumidamente, pode-se assinalar as seguintes conclusões:

1. A expansão demográfica referida a rede de localidades centrais balisada pela ideia de hierarquia urbana ganha mais consitência. Fica mais evidente o discernimento de quais são os principais grupos de localidades geográficas do país que irão se expandir ou retrair demograficamente e quais papeis deverão estar reservados a elas na conjunção das dinâmicas demográfica e econômica.

2. A agropecuária, que é uma atividade intensiva em solo, territorialmente extensiva e comatividades estabelecidas por recentes reestruturações fundiárias é pouco sensível a mudanças de tendências no médio prazo. Nos próximos 20 anos deve consolidar-se até os limites da expansão física possível no chamado arco do desmatamento e ampliar seu desempenho na geração de riqueza. Se pelos dados de PIB entre 1999 e 2003 foi o setor que, relativamente, mais acumulou resultados positivos, tudo indica que continuará sendo um setor dinâmico, altamente gerador de divisas, não suscetível a rupturas ou mudanças drásticas. Como reúne atividades que operam com grandes economias de escala em propriedades amplamente mecanizadas que ocupam pouca mão-de-obra e expulsam pequenos proprietários, o resultado em termos de população residente não poderia ser diferente do mostrado na Figura 2: muitos municípios com saldos migratórios negativos.

3. A indústria, por seu turno, se interioriza, mas dissociada da territorialidade extensiva daagropecuária. Requer, em geral, localizações mais próximas de grandes cidades, sistemas de transporte, infraestruturas, maior proximidade dos reservatórios de mão de obra ou até da matériaprima conforme o ramo. Como muitas plantas industriais podem relocalizar-seespacialmente, em face dos efeitos das deseconomias de aglomeração e dos processos de reestruturação produtiva, ocorrem transferências intra ou inter-regional. Ao que tudo indica, boa parte dessas relocalizações ocorrem em uma expressiva área do interior paulista, como sugerem os primeiros mapas da Figura 2. Essas evidências, evidentemente, conferem com as conclusões da análise do PIB quando indicam que, no período 1999/2003, o setor mostrou aumento significativo de participação fora 
dos Centros Principais. A indústria, por sua vez, é um poderoso fator de estimulo ao setor de serviços em áreas urbanas vizinhas.

4. Os serviços por definição compõem-se de atividades que valem-se das economias deurbanização e de localização, compondo-as inclusive. Boa parte do setor engloba atividades que requerem mão-de-obra qualificada, mas prevalecem as que agregam mais trabalhadores de menores salários e baixa qualificação. Por outro lado, comparados aos dois outros setores, é o que mais atrai população e sua configuração eminentemente urbana confere com as tendências de crescimento apontadas nas projeções demográficas. Ou seja, os grandes centros urbanos e até determinadas cidades médias tendem a continuar sendo núcleos densos com população predominantemente ocupada nos serviços, principalmente nos serviços pessoais, domésticos e sociais.

Por último, convém sublinhar que a desconcentração demográfica e econômicaseguirá seu curso nos próximos 20 anos, em ritmo mais ou menos lento, dependente do desempenho da indústria e da agropecuária, partícipes decisivos do processo de interiorização da urbanização, porquanto sem eles não desenvolvem de forma sustentada os diversos tipos de serviços que tipificam a rede de localidades centrais, a principal rede geográfica de capitais fixos que articula pessoas, atividades e lugares.

\section{REFERÊNCIAS BIBLIOGRÁFICAS}

ANDRADE, T. A., SERRA, R. V (Org.). Cidades médias brasileiras. Rio de Janeiro: IPEA, 2001.

DAVIDOVICH, F. (1989). Tendência da urbanização no Brasil, uma análise espacial. IN: REVISTA BRASILEIRA DE GEOGRAFIA, ano 37, v. 51, n. 1, jan/mar, 1989.

DINIZ, C.C. Desenvolvimento poligonal no Brasil; nem desconcentração, nem contínua polarização. Belo Horizonte, NOVA ECONOMIA (Revista do Departamento de CiênciasEconômicas da UFMG). V.31. N.11. Set. p. 35-64. 1993.

EGLER, Cláudio A.G. Crise e dinâmica das estruturas produtivas regionais no Brasil. In: CASTRO,

Iná, et.all. (orgs). Brasil: Questões atuais da reorganização do território. Rio de Janeiro: Bertrand Brasil, 1996.

GARCIA, R A; CARVALHO, J. A. M. The estimates of the Brazilian international net migration and the Brazilian emigrants, based on the method of inter-census survival ratio (ISR). In: XXV INTERNATIONAL POPULATION CONFERENCE, 2005, Tours. XXV INTERNATIONAL POPULATION CONFERENCE, 2005.

GEIGER, Pedro Pinchas. Observações sobre a organização urbana no Brasil, in Evolução da Rede Urbana Brasileira. Instituto Nacional de Estudos Pedagógicos: Rio de Janeiro, 1963.

Cadernos do Leste

Artigos Cientificos

Belo Horizonte, Jan.-Dez. Vol.9, n9, 2009 
IBGE. Produto Interno Bruto dos Municípios. Série relatórios metodológicos. Rio de Janeiro: IBGE, 2004. 49 p.

IBGE. Regiões de influências das cidades, Revisão atualizada do estudo Divisão do Brasil em Regiões Funcionais Urbanas. IBGE, Rio de Janeiro, 1987. 183p.

IPEA. Relatório Final do Estudo: Caracterização e Tendências da Rede Urbana do Brasil. Brasília.1999.

MALTHUS, T. O princípio da população - última versão (1824). Coleção Grandes Cientistas Sociais. Economia. pp. 148 -194.

MATOS, Ralfo. A contribuição dos imigrantes em áreas de desconcentração demográfica do Brasil contemporâneo. Revista Brasileira de Estudos da População. Campinas, v. 19, n. 1, p. 49-74, 2002

e BRAGA, F. G. Migração e rede urbana: procedências e inserção ocupacional. In:

XIII Encontro Nacional de Estudos Populacionais, Ouro Preto, 2002.

e FERREIRA, R. N. Caracterização da Rede de Localidades Urbanas Centrais do Brasil ao final do século XX. In: Matos, Ralfo (org). Espacialidades em rede: população, urbanização emigração no Brasil contemporâneo. Belo Horizonte, v. 1, p. 89-109, 2005.

MOTTA, Diana M. e AJARA, Cesar. "Rede urbana brasileira-hierarquia das cidades". Curso de Gestão Urbana e de Cidade EG/FJP-WBI-PBH-ESAF-IPEA, ago, 1999.

PRESTON, S. H. HEUVELINE, P. GUILLOT, M. Demography. Measuring and Modeling Population processes. Massachusetts: Blackwell Publishers, 2000, p. 03-20.

Cadernos do Leste

Artigos Cientificos

Belo Horizonte, Jan.-Dez. Vol.9, n9, 2009 